\title{
Dynamics of Protein Tyrosine Nitration and Denitration: A Review
}

\section{Sengupta $S$ and Bhattacharjee $A^{*}$}

Department of Microbiology, University of North Bengal, Raja Rammohunpur, Siliguri, Darjeeling, West Bengal, India

${ }^{*}$ Corresponding author: Bhattacharjee A, Assistant Professor, Department of Microbiology, University of North Bengal, Raja Rammohunpur, Siliguri, Darjeeling, West Bengal, India 734013, Tel: +919674665722, E-mail: aribiochem@gmail.com

Citation: Sengupta S, Bhattacharjee A (2016) Dynamics of Protein Tyrosine Nitration and Denitration: A Review. J Proteo Genomics 1(1): 105

Received Date: October 04, 2016 Accepted Date: December 17, 2016 Published Date: December 18, 2016

\begin{abstract}
Protein tyrosine nitration (PTN) is a post-translational modification that occurs under the action of Nitric oxide (NO) which leads to the formation of reactive nitrogen species (RNS). RNS reacts with tyrosine residues in proteins to form nitrotyrosine. PTN has lately been related to neurodegenerative diseases. It is very essential to know the details of its mechanism. PTN is also involved in cellular signaling. The detail of such an event is still not clear. Controlling of cellular signaling is only possible if nitration and denitraton is a dynamic, regulated and reversible process. In this review the biological consequence of PTN, analytical methods required for their detection and their relation with different neurological diseases has been discussed in details. This review is the first of its kind where the use of bioinformatics tools for detection of nitrotyrosine has been discussed comprehensively. The review gives a detailed account of the existing softwares, databases and their uses for the study of PTN and denitration. Moreover the functioning of the probable denitration pathways and associated impacts on cellular signaling and physiology have also been addressed in detail. Although previous reviews on PTN are limited only to its formation, function, analysis or denitration of nitrated proteins separately but integrating them to provide the broader picture and relevance in biological system was absent. This work is aimed at to bridge that lacunae also provide insights about the identification and detection of interactive components in a protein nitration-denitration pathway.

Keywords: MProtein Tyrosine Nitration; Nitric Oxide; Neurodegenerative Diseases; Denitration; Bioinformatics Tools

List of Abbreviations: $\mathrm{NO}_{2}$-TYR: Nitrotyrosine; RNS: Reactive nitrogen species; NO: Nitric oxide; PTN: Protein Tyrosine Nitration; GSH: Reduced glutathione; GSSG: Oxidized glutathione; MnSOD: Manganese superoxide dismutase; HDAC2: Histone Deacetylase 2; COX: Cyclooxygenase; LDL: Low-density lipoprotein; HDL: High-density lipoprotein; HPLC: High Performance Liquid Chromatography; $\mathrm{NH}_{2}$-TYR: Aminotyrosine; GC-MS: Gas Chromatography-Mass Spectroscopy; 2DGE: Two-Dimensional Polyacrylamide Gel Electrophoresis; LC-MS/MS: Liquid chromatography-tandem mass spectroscopy
\end{abstract}

\section{Introduction}

Stress is a situation in which the cellular redox homoeostasis is altered because of excessive production of different reactive species eg. reactive oxygen species (ROS), reactive nitrogen species (RNS) [1]. The stress which is mediated by ROS like singlet oxygen, superoxide, $\mathrm{H}_{2} \mathrm{O}_{2}$ and hydroxyl radicals known as oxidative stress [2]. ROS are produced during cell cycle progression, cell differentiation, cell signaling [3,4]. It can damage the macromolecules like membrane lipids [5], proteins [6] and DNA [7]. In analogy to oxidative stress, the term 'nitrosative stress' involves reactive nitrogen species (RNS) where the ratio of nitrosants to antioxidants is $>1$. RNS are produced due to the reaction of ROS with Nitric oxide (NO•). During nitrosative stress different types of RNS cause nitrosylation of biomolecules thereby creating an imbalance in the production and the exclusion of reactive nitrogen and oxygen intermediates of the body [8]. One of the major marker of nitrosative stress is the formation of 3-Nitrotyrosine $\left(\mathrm{NO}_{2}-\mathrm{TYR}\right)$, a stable post-translational modification of protein. In vivo it forms due to the reaction between tyrosine residues and nitrating agents. During the formation of 3-Nitotyrosine a nitro group $\left(-\mathrm{NO}_{2}\right)$ is added in the ortho position of the phenolic hydroxyl group of tyrosine. Mostly the natural abundance of tyrosine residues is about $3 \%$ in proteins. Tyrosine may be nitrated through numerous chemical reactions. This modification introduces a net negative charge at neutral $\mathrm{pH}$, which triggers changes in the local physiological and chemical environment of the biomolecule. Nitration of tyrosine residues often indicates loss of protein activity. Alteration of the structure and function of protein due to formation of nitrated tyrosine may change the rate of proteolytic degradation [9]. Moreover presence of high amount of RNS or non-functional antioxidant systems, target proteins can also be nitrated at specific tyrosine residues [10]. 
3-Nitrotyrosine formation is associated with cell signaling and disease initiation and progression like neurodegenerative diseases, cardiovascular injury and cancer. It even facilitates in the accumulation of nitrated proteins in vivo [11]. The most common neurodegenerative diseases are Alzheimer's disease, Huntington's disease and Parkinson's disease etc. These Diseases are also referred to as proteinopathies due to the aggregation of proteins [12]. Loss of synapses and neurons in the certain subcortical regions and cerebral cortex is a characteristic feature of Alzheimer's disease. This loss indicates the degeneration of parietal and temporal lobe of the brain and also parts of the cingulate gyrus and frontal cortex [13]. Alzheimer's disease is triggered by accumulation of misfolded $\alpha \beta$ and nitrated tau proteins in the brain [14]. Accumulation of intracellular toxic proteins and late onset are both essential features of Huntington's disease and Parkinson's disease. Not only PTN is related to diseases but it is also related to cellular signaling. Different proteins of signaling pathway of mating type Saccharomyces cerevisiae is nitrated [15]. Beside these the mitochondrial proteins like aconitase, isocitrate dehydrogenase are also reported to be nitrated in Saccaromyces cerevisiae [16]. Thus the accumulation of only nitrated proteins subsets is dependent on the conversion of nitrated proteins to its denitrated form and vice-versa [17]. But the evidences of denitration process are very less. The fine tune between the balance of nitration and denitration is yet to be elucidated. Although PTN as of now is a stable post-translational modification, but the role of nitrated protein in cellular signaling and physiology is slowly emerging.

Several biochemical systems are present to counteract the nitrosative stress [1]. Among them Low molecular weight thiols play an important role to counteract the nitrosative stress and also maintain the redox homeostasis. One of the important low molecular weight thiol is reduced glutathione (GSH) which is oxidized to GSSG by the action of glutathione peroxidase (GPx) in the elevated amount of NO• to maintain the cellular homeostasis. GSSG is again converted back to GSH by the activity of glutathione reductase. The ratio of the concentration of GSH and GSSG is associated with the redox homeostasis [18]. Macromolecules like enzymes can also counteract stress condition [1]. Catalases can counteract the activity of RNS. It is reported that catalases can detoxify the effect of peroxynitrite in vivo [19]. Superoxide dismutase [20], Cytochorme C [21] are also reported as the antinitrosative enzymes but the activity of these enzymes are also inhibited by nitration [22,23]. Thus the antinitrosative and denitration system is a topic of ongoing research.

In this review we have discussed about the cellular function of PTN and relation of PTN to the neurodegenerative diseases and we have attempted to give a hypothesis to arrest the denitration system (i.e. the system by which organisms can counteract the PTN) by using the proteomics tools [15,17].

\section{Agents of Nitration}

$\mathrm{NO} \bullet$ is an endogenously and enzymatically generated molecule which contributes diversely to physiological functions [24]. NO• is a very reactive molecule as it contains unpaired electron that permits rapid reaction with diverse molecules [25] and form reactive nitrogen species that can nitrify the protein tyrosine [26]. NO• is formed during the Conversion of L-arginine to L-citrulline. The first step is the formation of intermediate $\mathrm{N} \omega$-hydroxy-L-arginine (NHA). This reaction is catalyzed by Nitric oxide synthases (NOSs). NHA is again oxidized to form NO• [27]. The post-translational modification through NO• is a non-classical NO• signaling, which is cGMP-independent [28]. But NO. also plays an important role as signaling molecule [29] in neurotransmission, vasodilation [30], and immune response in vivo therefore regulation of the activity of NOSs (specially iNOS) to synthesis NO•, is associated with many diseases [31-35].

\section{Derivatives of Peroxynitrite}

Peroxynitrite (ONOO-) is synthesized quickly on reaction of nitric oxide (NO•) with superoxide anion $\left(\mathrm{O}_{2}^{-\bullet}\right)$ [36]. Superoxide is produced in various biochemical reactions because of the electron flow through the mitochondria which can interact with NO to form peroxynitrtite [37]. Peroxynitrite can also be synthesized in vivo through the reaction of molecular oxygen with nitroxyl anion ( $\mathrm{NO}^{-}$) [38]. Most of the time peroxynitrite reacts with carbon dioxide in cellular fluids and synthesize $\mathrm{ONOOCO}_{2}^{-}$, which is decomposed by two ways- one gives carbon dioxide and nitrate, and the other carbonate radical anion and nitrogen dioxide $\left(\mathrm{NO}_{2}\right)$. The second way is the key pathway of protein tyrosine nitration via peroxynitrite. This adduct of peroxynitrite-carbon dioxide may cause nitration directly via $\mathrm{NO}_{2}^{+}[39]$ (Figure 1).

\section{Nitrate and Nitrite}

Nitrates and nitrite can be another source of nitric oxide apart from L-Arg nitric oxide synthases. There are several enzymatic as well nonenzymatic pathway to from NO• from Nitrate and nitrite in vivo [40]. Nonenzymatic NO• formation from nitrate esters involves interaction with thiol groups. Further, thiols are oxidized to their respective disulfides and nitrite. A sigmoidal thiol dependence was found for NO formation, suggesting a more complex reaction mechanism. The rate of reaction between nitrate and thiol increases at alkaline $\mathrm{pH}$ [41]. Protein tyrosine can be nitrated by $\mathrm{NO}_{2} \bullet$ radicals. This radical is formed through the reaction of nitrite and hydrogen peroxide by various hemoperoxydases. It is one of the key mechanism of PTN [42]. Nitrous acid is formed by acidification of nitrite and sometimes nitryl chloride $\left(\mathrm{NO}_{2} \mathrm{Cl}\right)$ [43]. This nitryl chloride is a potent nitrating agent. Certain metalloproteins comprising hemoglobin, cytochrome c, superoxide dismutase catalyze $\mathrm{H}_{2} \mathrm{O}_{2}$ dependent oxidation of nitrite to form 3-nitrotyrosine [44]. 


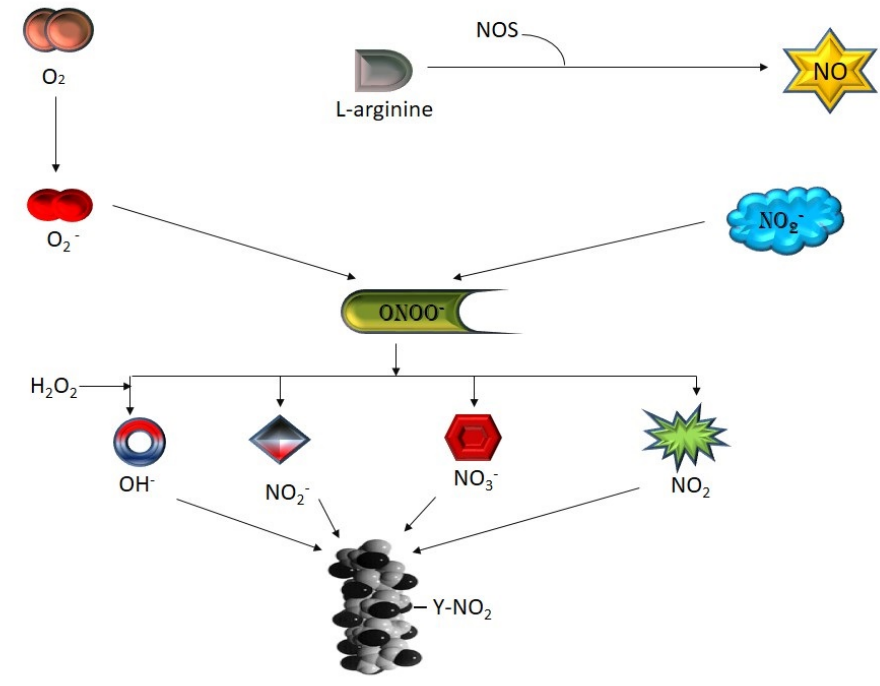

Figure 1: Formation of different reactive species from peroxynitrite

\section{S-nitrosoglutathione (GSNO)}

Exposure of GSH to $\bullet \mathrm{NO}$ can lead to formation of S-nitrosoglutathione (GSNO) [45]. GSNO is a source of $\bullet$ NO, and its plays an important role in $\bullet \mathrm{NO}$ mediated signaling. S-nitrosothiol can also imitate the effects of endogenous $\bullet$ NO because $\bullet$ NO is released during GSNO decomposition [46]. It has already been reported that GSNO can up regulate the activities of catalase and SOD (Superoxide Dismutase) to combat oxidative/ nitrosative stress in yeast [47]. In vivo S-nitrosothiols has an important role in controlling protein function and structure together with also in $\bullet$ NO transport and signaling [48]. Redox homeostasis is maintained by glutathione (GSH). In case of mammalian cells glutathione is involved in transport of amino acid, detoxification of xenobiotic and deoxyribonucleotides and inhibition of platelet activation [49-51].

\section{Biological importance of Protein Tyrosine Nitration}

\section{PTN and Protein Function}

Protein tyrosine nitration may alter the function of proteins [52]. Tyrosine though may be the major target for nitration but cysteine and methionine can be nitrated too [53]. For example in the case of MnSOD (Manganese superoxide dismutase), substrate $\left(\mathrm{O}_{2}{ }^{-}\right)$is diffused towards the $\mathrm{Mn}$ center due to the steric restriction which is imposed by $-\mathrm{NO}_{2}$ group. It causes a fall in the pKa of the $-\mathrm{OH}$ group of tyrosine. In the active site a negative charge is formed due to the nitration of a tyrosine residue, which results in the electrostatic repulsion of $\mathrm{O}_{2}{ }^{--}$and alteration of the redox potential and arrangement of hydrogen bonding [54]. It was reported that the peroxynitrite can inhibit the activity of MnSOD of Arabidopsis by nitration at Tyr63 residue [22]. In the nitrating conditions cytochrome $\mathrm{c}$ results in nitration at adaptable positions cytochrome $\mathrm{c}$ tyrosine. Whereas nitration of cytochrome $\mathrm{C}$ by peroxynitrite causes preferential modification of tyrosine residue, leading to mono nitrated forms of tyrosines moderately distant from the active site [54]. Reports suggest that the activity of HDAC2 (Histone Deacetylase 2) is inhibited due to the tyrosine-253 nitration. This nitration also causes prompt proteasomal degradation of HDAC and due to this event gene regulation is affected in vivo. This study explores HDAC inhibitors as the novel cancer therapies [55]. In a recent study NF- $\kappa \mathrm{B}$ mediated mechanism

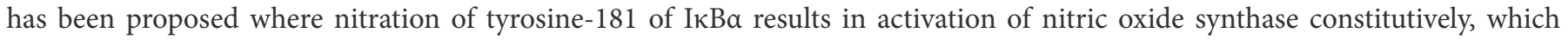
causes dissociation of intact I $\kappa \mathrm{B} \alpha$ from NF- $\kappa \mathrm{B}$ and this mechanism doesn't seem to involve proteolytic degradation of I $\mathrm{B} \alpha$ or I $\kappa \mathrm{B} \alpha$ kinase-dependent phosphorylation [56]. This activation of NF- $\kappa \mathrm{B}$ leads to inflammation [57]. In another study activation of carbamoyl phosphate synthetase 1 (CPS1) is prevented by activator N-acetyl-L-glutamate (NAG) due to the nitration at Y1450 in an $\alpha$-helix of allosteric domain [58]. One of the major enzyme Ascorbate peroxidase regulates ascorbate-glutathione cycle which is very important for the detoxification of cellular $\mathrm{H}_{2} \mathrm{O}_{2}$. But the activity of Pea Ascorbate peroxidase is inhibited due to the protein tyrosine nitration. It is revealed that Tyr5 and Tyr235 residues were nitrated by peroxynitrite [59]. A study revealed that high amount of NO. can inactivate NADPH oxidase thus self-amplification loop is slowed down [22].

\section{PTN and Pathological Conditions}

Specific tyrosine residues of diverse proteins are nitrated both in vivo and in vitro condition by the reactive molecules like peroxynitrite [60]. The presence of 3-nitrotyrosinated proteins is apparent histochemically in infected or inflamed tissues. Protein nitration may be profoundly associated to oxidative cell injury indicating its role in altering the protein function. The structure of the proteins is also changed due to the nitration and the distorted proteins may act as antigens thus antibodies are generated against selfproteins [61]. The immune reactivity of 3-nitrotyrosine has been conveyed in numerous human pathological condition. Increased 
levels of 3-nitrotyrosine is associated with different human diseases such as multiple sclerosis, atherosclerosis, Parkinson's disease (PD), Alzheimer's disease (AD), amyotrophic lateral sclerosis (ALS), stroke, cystic fibrosis, lung diseases, asthma, myocardial malfunction, diabetes, cirrhosis, chronic hepatitis, etc. [62].

\begin{abstract}
Alzheimer's disease: Nitration of the tau protein is the cause of Alzheimer's disease [63]. It is characterized by neurofibrillary tangle formation due to tyrosine nitration and self-assembly of tau protein [64]. Tau is a microtubule associated protein (MAP) encoded on chromosome 17. Splicing leads to the formation of six canonical isoforms in the central nervous system containing different N-terminal inserts and microtubule binding repeats [65]. Endogenous tyrosine residues prone to be nitrated in tau protein are at 18,29,197,310, and 394 position (numbers correspond to the longest tau isoform, which contains441 amino acids). In vitro, selectively of $\mathrm{ONOO}^{-}$mediated tyrosine nitration is mostly seen at $\mathrm{N}$-terminal region of the tau molecule (Y18, Y29) and less at Y197 and Y394. Nitration at Y310 was rarely observed, probably because of its location within the hydrophobic microtubule binding repeat of tau [66]. Generation of $\mathrm{ONOO}^{-}$is associated with $\alpha \beta$ plaques formation [67]. $\alpha \beta$ accumulated in mitochondrial matrix and affect the mitochondrial enzymes. So there is a decrease in brain energy metabolism [68].
\end{abstract}

Parkinson's disease: The main cause of PD is tyrosine nitration of $\alpha$-Synuclein ( $\alpha$-Syn) protein. All the four tyrosine residues of a-Syn are susceptible to be nitrated which are located at 39 (at the N-terminal region), 125, 133 and 136 (at the C-terminal region) [69]. a-Syn is very sensitive to nitrating agents and the protein is nitrated even at low concentration of peroxynitrite. In the presence of peroxynitrite the tyrosine residues are oxidized to form dimers which lead to oligomer formation [70]. After exposing to nitrating agent, elevated rate of dimer and oligomer formation is mediated via Tyr-125 and Tyr-39 nitration respectively [71,72]. The rate of fibril formation is accelerated by Monomeric or dimeric nitrated a-syn but the fibril formation is inhibited by nitrated a-syn oligomers [73].

Atherosclerosis: Another major disease resulting from protein tyrosine nitration is Atherosclerosis [74]. Approximately 0.001 to $0.01 \%$ tyrosine residues of plasma proteins are found to be nitrated in cardiovascular disease [75]. In this disease COX (Cyclooxygenase) gets nitrated [76]. COX plays an important role in prostaglandin biosynthesis. The enzyme catalyses the metabolism of arachidonic acid which is a key step in prostaglandin biosynthesis. A heme dependent nitration of Tyr385, present at the catalytic site of COX results in its inactivation [77]. Such nitration may also render the protein susceptible to proteolysis [74]. Different studies showed that nitration of LDL (Low-density lipoprotein), HDL (High-density lipoprotein), can lead to plaque formation, increased platelet aggregation, clotting and disruption in cholesterol transport which may also lead to atherosclerosis $[74,78,79]$.

\title{
PTN and Tyrosine Phosphorylation
}

Nitration of tyrosine may interfere with the formation of tyrosine phosphorylation, which may affect cellular functions [80]. In vivo signal transduction is regulated by tyrosine phosphorylation. It is also associated with different cellular responses and growth factors. The neutral $-\mathrm{OH}$ group of tyrosine is phosphorylated by tyrosine kinases. The $\mathrm{pk}_{\mathrm{a}}$ value of the $-\mathrm{OH}$ group of tyrosine gets shifted due to nitration thereby affecting tyrosine phosphorylation [17]. Sometimes a reverse situation can also be seen. The phosphorylation of protein tyrosine can constrain the PTN. A study showed that the phosphorylation of tyrosine of cdc2 is prevented by peroxynitrite-mediated PTN [82]. Nitration in $130^{\text {Cas }}$, an adhesion complex protein, prevents tyrosine phosphorylation, indicating that the assembly of focal adhesion complexes may get affected by this process [83]. It is also seen in different studies that the tyrosine sites are different for nitration and phosphorylation in a same protein. Tyrosine residue in extracellular signalrelated kinase (ERK) 1/2 can be nitrated by stimulation of Angiotensin II which may facilitates the activation of phosphorylatio but the sites for phosphorylation and nitration is different [84]. A very present study revealed that the phosphorylation of PLK3 at S129 cannot be prevented by the nitration of $\alpha$-syn at any tyrosine residue and also PLK3 phosphorylates nitrated dimers, trimers, and oligomers [85]. Hence the general idea is that protein tyrosine nitration and phosphorylation are mutually exclusive process which plays an important role in cellular signaling [86]. Tyrosine phosphorylation is dependent on the concentration of nitrating agents like peroxynitrite. Competition occurs for the same sensitive tyrosine residue for phosphorylation or nitration. While tyrosine phosphorylation is induced at lower concentration of peroxynitrite, at relatively higher concentration the process gets inactivated and it is also irreversible. But till now the competition-correlation between phosphorylation and nitration is poorly understood $[87,88]$ (Figure 2).

\section{PTN and Mitochondria}

The primary locus for PTN in mitochondria is matrix proteins [89]. Different reactive oxygen species are formed during the electron transport chain in mitochondria [90] which may react with nitric oxide to form Peroxynitrite. Peroxynitrite thus formed, can diffuse from extra mitochondrial compartments into mitochondria or it may be formed intramitochondrially [91]. Aconitase, a key enzyme of TCA cycle is inhibited by peroxynitrite. It disrupts the enzyme's Fe-4S cluster through the formation of PTN. Other proteins like TOM 71, Putative flavin-dependent monooxygenase, isocitrate dehydrogenase etc. proteins can also be nitrated. The activities of these enzymes are lost due to PTN [16]. MnSOD is another enzyme whose activity can be inhibited by PTN [92]. MnSOD inhibits the formation of peroxynitrite by dismutating superoxide. This inactivation of MNSOD leads to nitration of other key proteins of mitochondria [93]. This nitration compromises antioxidant defenses which may lead to apoptosis and structural 
alteration of protein [94]. Some studies indicate the presence of a denitration mechanism within the mitochondria which is oxygen tension-dependent but protease-independent [95]. Total PTN increased in mitochondria when whole organs were exposed to ischemic hypoxia. The denitration of several mitochondrial enzymes during the hypoxic-anoxic phase may help to sustain mitochondrial ATP production and an increased antioxidant capacity, which is important for the prevention of metabolic failure and cell death during oxygen deprivation [90]. Such reports lead to the hypothesis that within mitochondria protein modification by nitration is reversible which is maintained by concerted effect of a nitration-denitration system [96].

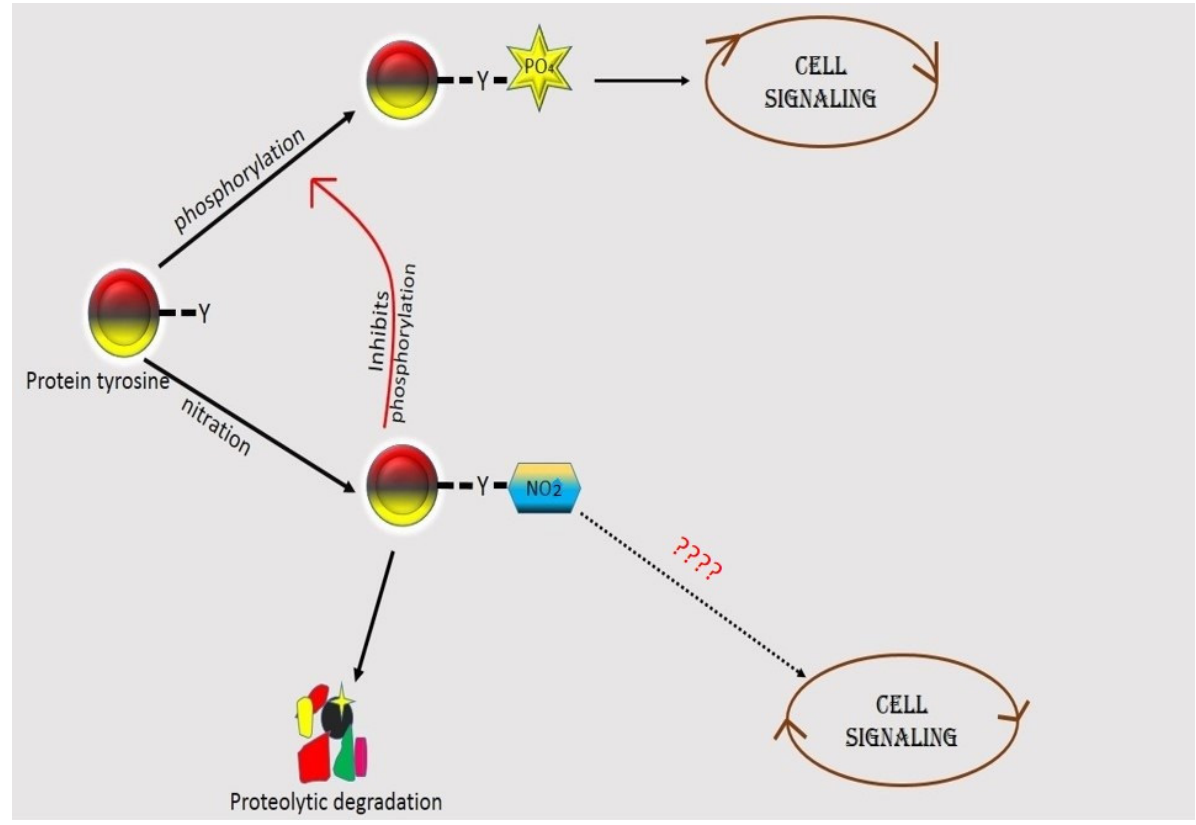

Figure 2: Schematic diagram of the role of nutrition and phosphorylation on tyrosine

\section{Denitration}

Elucidating the denitration process in vivo is still a challenge for the scientists. For decades PTN was thought to be a stable post-translational modification but in several studies with different proteins like HDL-containing plasma lipoprotein fractions [97], isolated platelets [98], activated macrophages [99] and calmodulin, the presence of a selective denitration mechanism was observed in vitro. Denitration is a selective process of like nitrated COX-1 protein isolated from macrophages, human and murine endothelial cells, and different tissue samples is one of the substrate for denitration. Denitration of nitrated COX-1 was quantified and validated by HPLC (High-Performance Liquid Chromatography) with electrochemical detection. This denitration activity was time and concentration dependent and it was inactivated by heating and proteolysis suggesting the association of a protein [100]. Another study showed that inspite of a lack of a nitratase activity albumin can remove ONOO- from the blood circulation using a $\mathrm{Ca}^{2+}$-dependent pathway with the concomitant increase of nitrated albumin [97,101]. A Ca ${ }^{2+}$-dependent denitration process was also seen in HDL and LDL -containing samples of heart and brain homogenates where nitrate ion concentration increased stoichiometrically with the denitration process [97]. Another calcium-dependent denitration system was seen in freshly isolated platelets in which nitro group was directly removed from tyrosine residues without being reduced to aminotyrosine ( $\left.\mathrm{NH}_{2}-\mathrm{TYR}\right)$ [102]. Reduction of nitrotyrosine to aminotyrosine is purely a chemical process mediated by agents like DTT (Dithiothreitol) and $\mathrm{Fe}^{3+}$-containing heme. Proteins like hemoglobin and myoglobin are also capable of catalyzing such reduction reaction [103]. A very recent study with Saccharomyces cerevisiae showed that 14 nitrated proteins involved in signal transduction pathway as well as the cellular functions also have an important role in mating signaling pathway. The functional interaction of these 14 nitroproteins is revealed by network analysis and other bioinformatic tools. One of the important protein for mating signaling, YPD1, is activated by nitration which helps it to stimulate pheromones. The regulation of such a protein between its active and inactive state is assumed to be mediated by a nitration-denitration system [15]. Some studies indicate the presence of putative denitrase in vivo which can maintain the dynamics of protein tyrosine nitration and denitration [104-106]. But still the actual mechanism of such denitration is not clear.

\section{Analytical Methods to Detect Protein Tyrosine Nitration}

One of the low-yield biological processes is PTN. Thus highly selective and specific methods are needed to quantify 3-nitrotyrosine [107]. In last year's many methods are developed to detect either circulating free form of 3-nitrotyrosine or the form which is released after protein hydrolysis [108]. Depending on the disease and in the level of free nitrotyrosine and tyrosine-nitrated proteins are dependent on the type of disease as well as the tissue of interest [109]. The methods are not error free. Analysis of 3 -nitrotyrosine is the main drawback of these methods, for example concentration of individual nitrated protein [110]. 


\section{Two-Dimensional Polyacrylamide Gel Electrophoresis (2DGE)}

It is one of the effective methods to identify the PTN. The extensively used method to study nitroproteome is 2DGE followed by western blotting [95]. The most common antibody for immunobloting is the clone 1A6monoclonal antibody [111]. Other antibodies with high specificity for 3-nitrotyrosine are also used to detect nitrated proteins [112]. But non-specific binding is one of the major problems. To solve this problem reducing agents-mediated reduction of nitrotyrosine is applied [95]. But there is another problem that sodium dithionite is sensitive to atmospheric oxygen so less amount of proteins are only reduced [92]. For that sensitivity of sodium dithionite, aminotyrosine again back to nitrotyrosine due to the reoxidation. This event may lead to weak signal of 3-nitrotyrosine on dithionite-treated membranes [111]. Low abundance of 3-nitrotyrosine in protein, extreme pI, size, solubility of proteins are the important facors which are related to the success of 2DGE approaches.

\section{Immunochemistry}

Several immunehistochemistry are widely used to detect $\mathrm{NO}_{2}$-TYR. Different monoclonal and polyclonal antibodies are used in these studies to precipitate antigen-antibody complex. These antibodies are commercially available. But the antigen-antibody complex is not formed due to some reasons like pretreatment of the samples with reducing agents (e.g, dithionite), excess amount of $\mathrm{NO}_{2}$-TYR, treatment with nitrated bovine serum albumin [108].

\section{Ultraviolet-Visible Spectroscopy}

Though low abundance of pure samples and week sensitivity are the problems but still Ultraviolet-Visible Spectroscopy is used to quantify the free $\mathrm{NO}_{2}$-TYR as well as the $\mathrm{NO}_{2}$-TYR which are present in peptides and proteins. Due to the change in pK value of nitrotyrosine, the absorbance spectra can also be changed. Thus, the concentration of nitrotyrosine is quantified at the absorbance of $430 \mathrm{~nm}$ [113].

\section{High-Performance Liquid Chromatography (HPLC)}

In several studies nitro-tyrosine is quantified by HPLC. Enzymatic or acid hydrolysis is required to prepare the samples [114]. But the major problem of this technique is verification. Through $\mathrm{NO}_{2}-\mathrm{TYR}$ is stable to acid hydrolysis [115] but it is reported that $\mathrm{NO}_{2}-$ TYR is converted to $\mathrm{NH}_{2}$-TYR during acid hydrolysis.

Tyrosine and nitro-tyrosine, both are detected by using UV detector (absorbance maxima at $280 \mathrm{~nm}$ at $\mathrm{pH} 3.5$ ) which provides an output signal proportional to the absorption. More selective identification of $\mathrm{NO}_{2}$-TYR is achieved at the absorption spectra of 365 $\mathrm{nm}$ at $\mathrm{pH}$ 3.5. In this technique acid hydrolysis is also done [108]. A more sensitive electrochemical detector is also used to quantify the concentration of protein tyrosine nitration and denitration [100].

$\mathrm{NO}_{2}$-TYR can be detected by using fluorescence detector but it is not a fluorescent compound. At first fluorescent product is prepared by the reaction of nitrotyrosine and derivatizing reagent such as $o$-phthalaldehyde (OPA) or 7-fluoro-4-nitrobenzo-2oxa-1,3-diazole (NBD-F) to quantify the $\mathrm{NO}_{2}$-TYR [108].

\section{Gas Chromatography (GC)}

Nitrotyrosine can be detected by using gas chromatography. In this technique tetranitromethane treated sample is used and incubated in vitro. In this technique a thermal energy analyzer is used with gas chromatography. Minimum 0.5 ng $\mathrm{NO}_{2}$-TYR is detected per injection. GC-MS (Gas Chromatography-Mass Spectroscopy) is used to identify and isolate nitrated proteins of urinary metabolites as 3-nitro-4-hydroxyphenyllactic acid and 3-nitro-4-hydroxyphenylacetic acid [108]. But for GC-MS technique the proteins are not directly injected because amino acids are not volatile and thermally stable. To solve this problem functional group of PTN is modified to increase the thermal stability and volatility [107].

\section{Mass Spectrometry}

Nitrotyrosine can be detected by using mass spectroscopy equipped with standard nitrogen laser (337 nm) and delayed extraction optics [116]. In some studies nitrotyrosine is detected by very sensitive GC-MS method. In this technique protein are hydrolyzed by acid and then aminotyrosine is detected by GC-MS. Heptafluorobutyric anhydride (HFBA) is used in this technique. HFBA reacts with different functional groups like amines and hydroxyls. At first the carboxylic group of 3-nitrotyrosine is converted to n-propyl ester and then the derivatives reacts with HFBA and form a compound which is detected by negative ion chemical ionization mass spectrometry (NICI-MS). $\mathrm{NO}_{2}$-TYR of heart proteins of rat was quantified by this technique. $\mathrm{NO}_{2}-\mathrm{TYR}$ and TYR was diluted with the isotope of ${ }^{13} \mathrm{C}$-labeled analogues of these two molecules to quantify the level of tyrosine and nitrotyrosine [117]. Nowadays a developed mass spectroscopy approach LS-MS/MS is used to get the more accurate profile of PTN. Nanoflow LC-MS/MS (Liquid chromatography-tandem mass spectroscopy) was used to identify the peptides and proteins from different denitrase-containing fractions. The fractions were required to enrich on a DEAE-Sepharose anion exchange column because the amount of nitroprotein is very less in vivo [100]. 


\section{Bioinformatics tools}

Bioinformatic tools have a great impact on genomics and proteomics studies. Different tools are used in proteomics to identify the proteins, their structure and functions. One of the softwares TurboSEQUEST, is used for identification of nitrated protein [118]. Scaffold software which is used in these tools helps to compute protein and peptide probability for nitration [119]. The proteins having more than $90 \%$ probability are accepted [15]. During identification of the homologs of different proteins by MS-BLAST the de novo sequences are correctly tagged. But the sequence tagging is error-prone. To solve this problem another prevalently used software SPIDER is used where both the errors, de novo sequencing and homology mutations are taken into account [120].

Tyrosine residues which are present in loop are more susceptible for nitration. Thus secondary structure of protein is important factor to predict [121]. Secondary structure of proteins can be determined by using different algorithms e.g. PSIPRED (Software for Protein Identification from Sequence Tags with De Novo Sequencing Error), JNET, PROF etc. [122-126]. One of the best methods to predict the protein structure is neutral network. The ability of PSI-BLAST is exploited by PSIPRED [122]. A more strong alignment profile is built by using PSI-BLAST. Compared to the conventional pairwise sequence searching methods, the more distant similarities are also included in this alignment profile [124]. JPred is used to predict the secondary structure of proteins. JPred4 is the latest version of JPred where JNet algorithm is used. JNet algorithm is one of the most error-free methods to predict the secondary structure of protein. One of the major characteristic of JPred 4 is higher accuracy. All the three states (-strand, -coil and -helix) of secondary structure of proteins can be predicted by JPred 4 with the $82 \%$ of accuracy. This accuracy is raised to $90 \%$ while solvent accessibility is predicted [127]. A useful software for characterizing the PTN site is GPS-YNO2 having 76.51\%, accuracy, 50.09\% sensitivity and $80.18 \%$ specificity from the leave-one-out validation [128].

The tyrosine residues which are exposed to solvent phase only available for nitration [121]. Thus Solvent accessibility is another important parameter to predict the protein structure because this parameter is related to the packing of amino acid residues and spatial arrangement during the protein folding. This parameter is also closely related to functions of proteins, protein-ligand interactions, protein-protein interactions [129]. Solvent accessibility is efficiently predicted by SANN, a nearest neighbor method.

Another bioinformatics method used to determine the role and interaction of a protein in certain protein pool is protein networking [130]. There are two major network models for proteomics- PIN (protein interaction network) and PSN (protein-signaling network). PIN is used in proteomics where protein-protein bindings are involved whereas PSN is used to study the mainly posttranslational modification like tyrosine nitration. There are several databases for protein interactions e.g. DIP, BIND, MIPS, MINT etc. DIP (The Database Interacting Proteins) contains only experimentally derived data of protein-protein interaction. It is one of the largest collection of publicly accessible protein-protein interaction information. The DIP data model consists of binary protein interactions along with information on each protein, the method used to determine the interaction, and a set of publication references to support the record. JDIP is stronger software which has the higher visualization power and decreases the problems with the increasing complexity and size of the data available in DIP [131]. DIP allows queries by proteins, BLAST, protein sequence motifs, and by journal article. An analysis of the confidence level of interaction in the DIP database has been published, and two types of confidence of interaction scores are available: PVM (paralogous verification method), assigns a higher reliability score to an interaction whose paralogs are also seen to interact in DIP. Another score is EPR (Expression Profile Reliability) has the ability to deem a set of protein-protein interactions more reliable if it has a similar expression profile as a higher-quality subset of DIP. But the score is only calculated for budding yeast because large amount of external information currently only available for budding yeast [132]. BIND (Biomolecular Interaction Network Database) is the one of the largest collection of freely available information about pairwise molecular interactions and complexes. Information about the interactions between two biological 'objects' like DNA, RNA, protein, gene, molecular complexes, small molecules are stored by BIND and the probable pathways are also stored by BIND. The specification of BIND data is available as XML DTD and ASN.1 [133]. MINT (The Molecular INTeraction database) contains data on the functional interaction between proteins. Mainly this consists of direct protein-protein interactions, but also includes indirect and genetic interaction. MINT can store enzymatic modifications and information on binding domains and kinetics [134]. MIPS mammalian protein-protein interaction database (MPPI) is a large collection of the data of high-quality experimental protein-protein interaction in mammals. Only experimental data are included here to maintain the quality. MySQL is the database where all these data are stored and these data are accessible through Perl CGI scripts, a web interface. Protein with all its neighbors is graphically represented by MIPS. It is a special feature of MIPS. The entire dataset can be downloaded in the standard format of PSI-MI for detail analysis. Different additional informations such as the experimental technique which are used, PubMed reference, probable sites for binding, and also the functional role of the protein-protein interaction are provided by MIPS [135].

Increase in the data content is a huge problem for visualization. One of the solutions of the problem is Cytoscape. Cytoscape is a stronger freely available, open-source java-based network visualization and analysis tool. Due to this ability non-programmers are allowed to plot the graphical images onto nodes and introduction of spreadsheet-like equations make it a stronger tool for integrating and visualizing complex datasets [136] (Figure $3 \mathrm{a}$ and $\mathrm{b}$ ).

These software's can be used to detect protein tyrosine nitration and denitration system. It will be easier to characterize proteins by using different bioinformatics tools. If several enzymes are involved in denitration system then the best choice to establish the probable pathway is protein networking. The secondary structure and Solvent accessibility are also very important to understand 
the structure and stability of the protein. The use of bioinformatics tools can be very helpful to characterize and establish the probable pathway of denitration system.

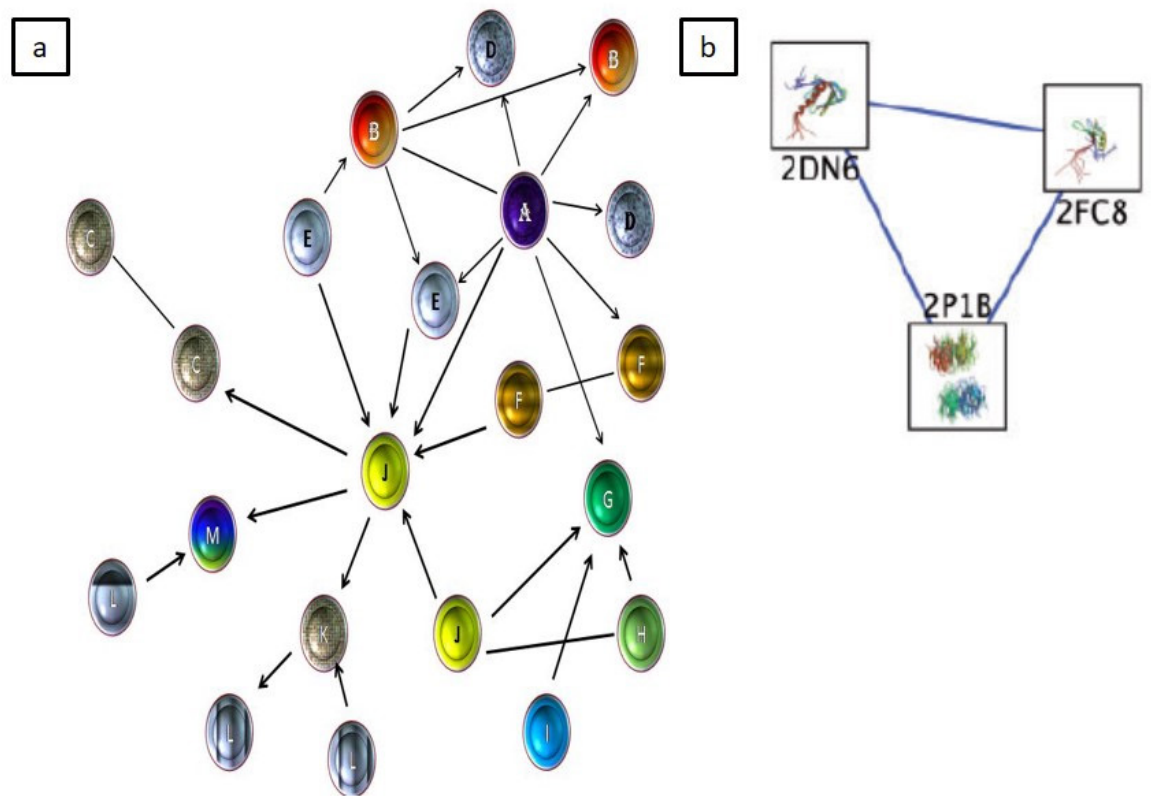

Figure 3: (a) A model of protein networking visualization by cytoscape; (b) Protein-protein interaction network visualization by cytoscape (adapted from Smooth ME et al. 2011)

\section{Probable Method to Detect Denitartion}

Low abundance of nitroprotein is the major problem to analyze 3-Nitrotyrosine as well as the dentration system. Some data suggest that denitration is an enzymatic process. But till now denitrase enzyme is not purified. So the purification is the challenge for the scientists. Our hypothesis is that to perform the western blot of cell free extract (CFE) and then treat the membrane of western blot with fractionated cell free extract (CFE). 2DGE and LC-MS/MS will be performed of the fraction which shows the highest denitration activity (Figure 4). If the dentration system is associated with several proteins, then protein networking has to be done (Figure 5).

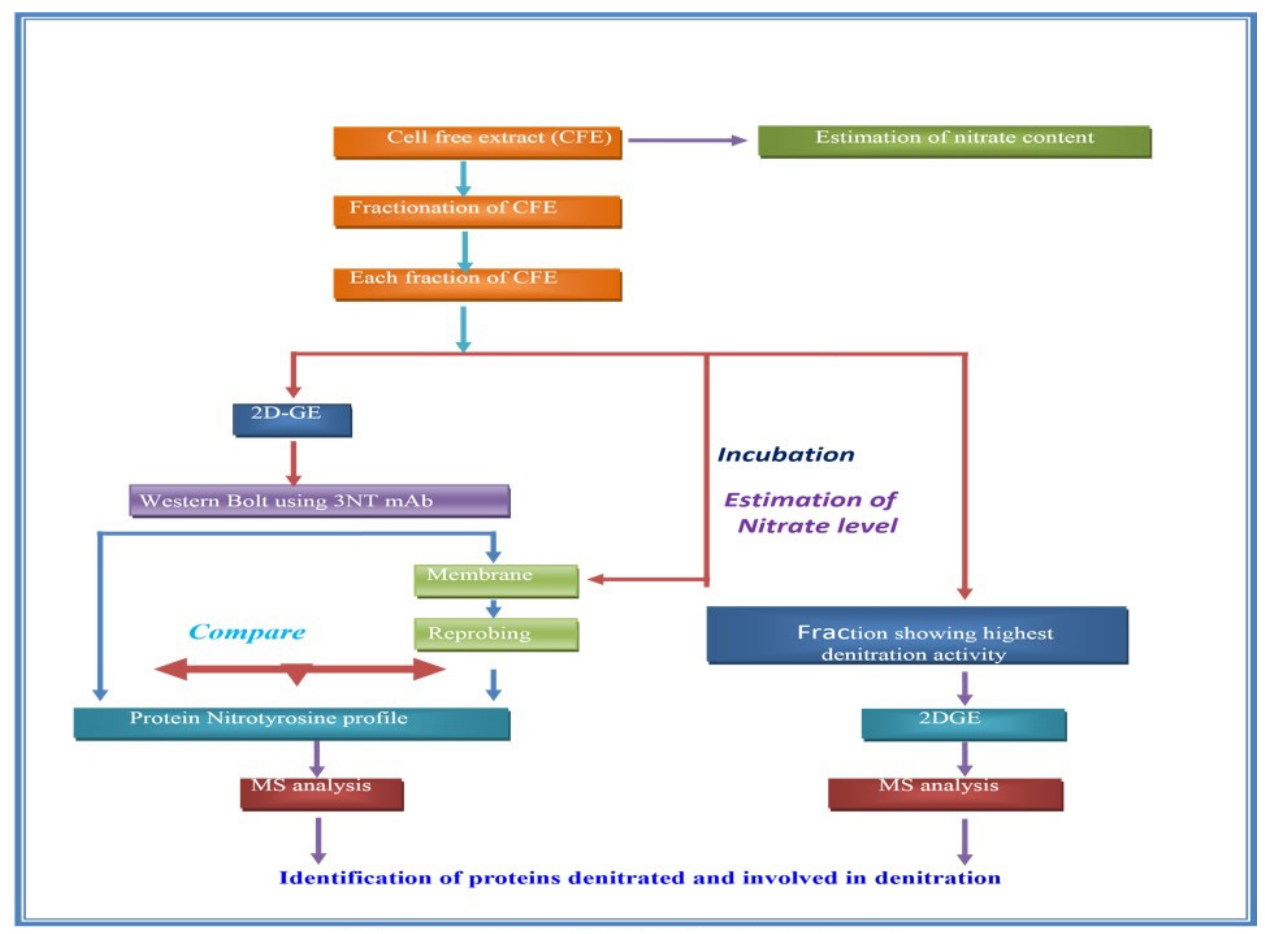

Figure 4: Probable method to detect "DENITRASE" enzyme 


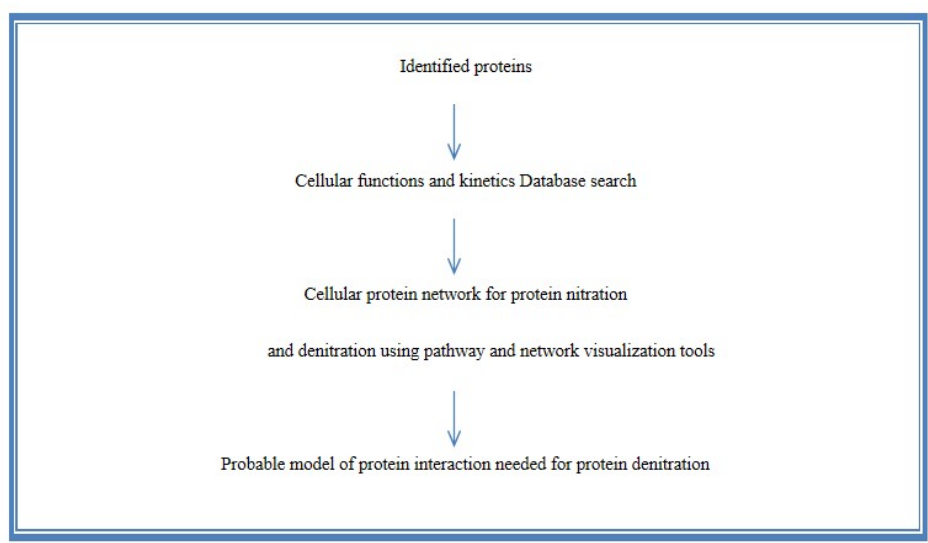

Figure 5: Approach for determining the cellular protein network for denitration

\section{Conclusion}

The study of PTN has gone through more than 50 years. Though it is a stable post translational modification but recent studies indicate that the process is reversible. But the in vivo role of PTN is still not very clear. There is almost no strong evidence of reversion of nitrated proteins. The biological significance of PTN is the study of interest in recent times. PTN is not only a simple in vivo one step reaction but it is related to signal transduction. But in human the altering of protein function by PTN is a fundamental fact that has been proved its drastic effects in neurodegenerative diseases. The main cause of neurodegenerative diseases is the tangle formation of neuroproteins. This event makes the proteins inactive. Denitration on the other hand is a mechanism that has been quite intriguing, foraying our perspective into a process that can alter nitration and thus may pave our way to a whole new world of perspectives where neurodegenerative diseases can be cured. Till now very few medicines are available for the remedy of these diseases. But these medicines have side effects. But the probability of using "denitrase" enzyme as a therapeutic medicine for the neurodegenerative diseases will be an interesting aspect to study. So the nitration-denitration pathway is very important to fully understand. If the nitration-denitration system is discovered in the microbes, a less complex cellular system then it will be the model for the higher eukaryotes and remedy for the neurodegenerative diseases because it is hypothesized that 'Denitrase' will prevent the oligomer formation [11,15,17,104-106] (Figure 6). But still isolation and application of 'Denitrase' is a challenge for scientist.

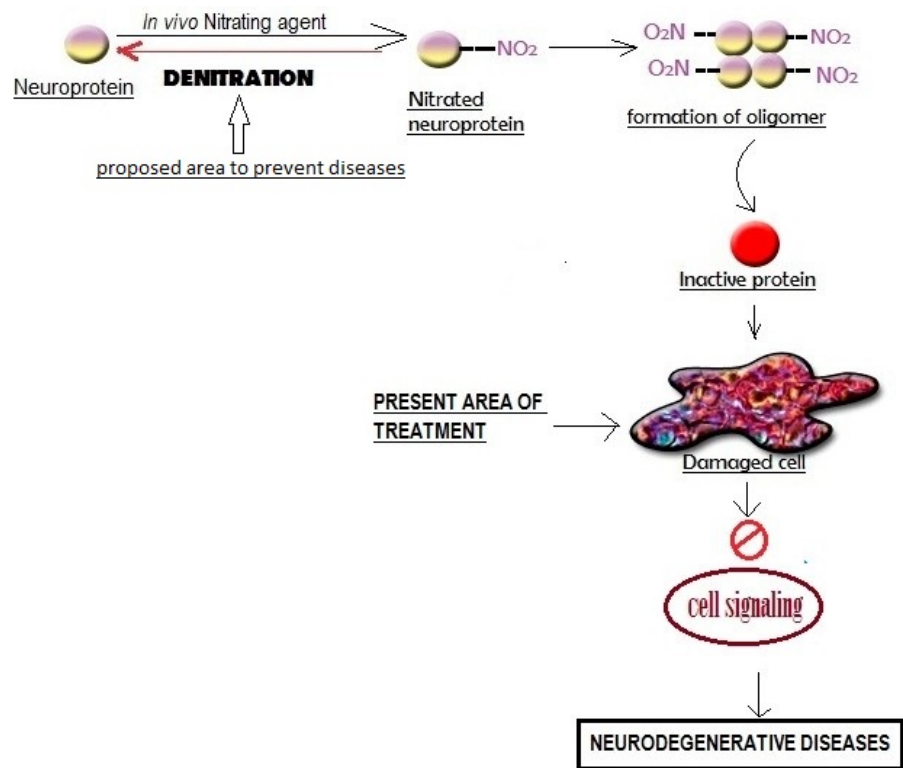

Figure 6: Future perspective to prevent the Neurodegenerative disease

\section{Acknowledgement}

The authors acknowledge the University of North Bengal for providing essential infrastructure to carry out this research.

\section{References}

1. Klatt P, Lamas S (2000) Regulation of protein function by S-glutathiolation in response to oxidative and nitrosative stress. Eur J Biochem 267: $4928-44$. 
2. Gille G, Sigler K (1995) Oxidative stress and living cells. Fol Microbiol 40: 131-52.

3. Lee AC, Fenster BE, Ito H, Takeda K, Bae NS, et al. (1999) Ras proteins induce senescence by altering the intracellular levels of reactive oxygen species. J Biol Chem 274: 7936-40.

4. Suh YA, Arnold RS, Lassegue B, Shi J, Xu X, et al. (1999) Cell transformation by the superoxide-generating oxidase Mox1. Nature 401: 79-82.

5. Gutteridge JM (1995) Lipid peroxidation and antioxidants as biomarkers of tissue damage. Clin Chem 41: $1819-28$.

6. Beckman KB, Ames BN (1997) Oxidative decay of DNA. J Biol Chem 272: 19633-6.

7. Berlett BS, Stadtman ER (1997) Protein oxidation in aging, disease, and oxidative stress. J Biol Chem 272: 20313-6.

8. Klandorf H, Dyke KV (2012) Oxidative and nitrosative stresses: their role in health and disease in man and birds. J Ag \& Bio Sci 3: 47-59.

9. Frears ER, Zhang Z, Blake DR, O'connell JP, Winyard PG (1996) Inactivation of tissue inhibitor metallo-proteinase-1 by peroxynitrite. FEBS Lett 381: 21-4.

10. Stadtman ER, Berlett BS (1998) Reactive oxygen-mediated protein oxidation in aging and disease. Drug Metab Rev 30: 225-43.

11. Lee JR, Kim JK, Lee SJ, Kim KP (2009) Role of protein tyrosine nitration in neurodegenerative diseases and atherosclerosis. Arch Pharm Res $32: 1109-18$.

12. Rubinsztein DC (2006) The roles of intracellular protein-degradation pathways in neurodegeneration. Nature 443: 780-6.

13. Wenk GL (2003) Neuropathologic changes in Alzheimer's disease. J Clin Psychiatry 64: 7-10.

14. Hashimoto M, Rockenstein E, Crews L, Masliah E (2003) Role of protein aggregation in mitochondrial dysfunction and neurodegeneration in Alzheimer's and Parkinson's diseases. Neuromolecular Med 4: 21-36.

15. Kang JW, Lee NY, Cho KC, Lee MY, Choi DY, et al. (2015) Analysis of nitrated proteins in Saccharomyces cerevisiae involved in mating signal transduction. Proteomics 15: 580-90.

16. Bhattacharjee A, Majumdar U, Maity D, Sarkar TS, Goswami AM, et al. (2009) In vivo protein tyrosine nitration in S. cerevisiae: identification of tyrosinenitrated proteins in mitochondria. Biochem Biophys Res Commun 388: 612-7.

17. Abello N, Kerstjens HA, Postma DS, Bischoff R (2009) Protein tyrosine nitration: selectivity, physicochemical and biological consequences, denitration, and proteomics methods for the identification of tyrosine-nitrated proteins. J Proteome Res 8: 3222-38.

18. Song M, Husain M, Jones-Carson J, Liu L, Henard CA, et al. (2013) Low molecular weight thiol-dependent antioxidant and antinitrosative defenses in Salmonella pathogenesis. Mol Microbiol 87: 609-22.

19. Sahoo R, Bhattacharjee A, Majumdar U, Ray SS, Dutta T, et al. (2009) A novel role of catalase in detoxification of peroxynitrite in S. cerevisiae. Biochem Biophys Res Commun 385: 507-11.

20. Yabuki M, Kariya S, Ishisaka R, Yasuda T, Yoshioka T, et. al. (1999) Resistance to nitric oxide-mediated apoptosis in HL-60 variant cells is associated with increased activities of Cu,Zn-superoxide dismutase and catalase. Free Radic Biol Med 26: 325-32.

21. Cross R, Aish J, Paston SJ, Poole RK, Moir JW (2000) Cytochrome from Rhodobacter capsulatus confers increased resistance to nitric oxide. J Bacteriol 182: $1442-7$.

22. Holzmeister C, Gaupels F, Geerlo A, Sarioglu H, Sattler M, et al. (2014) Differential inhibition of Arabidopsis superoxide dismutases by peroxynitrite-mediated tyrosine nitration. J Exp Bot 66: 989-99.

23. Radi R (2013) Protein tyrosine nitration: biochemical mechanisms and structural basis of its functional effects. Acc Chem Res $46: 550-9$.

24. Feldman PL, Griffith OW, Stuehr DJ (1993) The surprising life of nitric oxide. Chem Eng News 71: 26-38.

25. Pacher P, Beckman JS, Liaudet L (2007) Nitric oxide and peroxynitrite in health and disease. Physiol Rev 87: 315-424.

26. Beckman JS (1996) Oxidative damage and tyrosine nitration from peroxynitrite. Chem Res Toxicol 9: 836-44.

27. Davydov R, Labby KJ, Chobot SE, Lukoyanov DA, Crane BR, et al. (2014) Enzymatic and cryoreduction EPR studies of the hydroxylation of methylated N $\omega$ hydroxy-L-arginine analogues by nitric oxide synthase from Geobacillus stearothermophilus. Biochem 53: 6511-9.

28. Martinez-Ruiz A, Cadenas S, Lamas S (2011) Nitric oxide signalling: classical, less classical, and nonclassical mechanisms. Free Radic Biol Med 51: 17-29.

29. Jayakumari NR, Reghuvaran AC, Rajendran RS, Pillai VV, Karunakaran J, et al. (2014) Are nitric oxide-mediated protein modifications of functional significance in diabetic heart? Ye'S,-NO, wh'Y-NO't? Nitric Oxide 43: 35-44.

30. Ignarro LJ (2002) Nitric oxide as a unique signaling molecule in the vascular system: a historical overview. J Physiol Pharmacol 53: 503-14.

31. Dawson VL, Dawson, TM (1998) Nitric oxide in neurodegeneration. Prog Brain Res 118: 215-29.

32. Alderton WK, Cooper CE, Knowles RG (2001) Nitric oxide synthases: structure, function and inhibition. Biochem J 357: $593-615$.

33. Vallance P, Leiper J (2002) Blocking NO synthesis: how, where and why? Nat Rev Drug Discovery 1: 939-50.

34. Nakamura T, Lipton SA (2008) Emerging roles of Snitrosylation in protein misfolding and neurodegenerative diseases. Antioxid Redox Signal 10: 87-101.

35. Chung KK, David KK (2010) Emerging roles of nitric oxide in neurodegeneration. Nitric Oxide 22: 290-5.

36. Beckman JS (1996) Oxidative damage and tyrosine nitration from peroxynitrite. Chem Res Toxicol 9: 836-44.

37. Salvemini D, Doyle TM, Cuzzocrea S (2006) Superoxide, peroxynitrite and oxidative/nitrative stress in inflammation. Biochem Soc Trans 3: 965-70.

38. Kirsch M, de Groot H (2002) Formation of peroxynitrite from reaction of nitroxyl anion with molecular oxygen. J Biol Chem 277: 13379-88.

39. Poole RK, Hughes MN (2000) New functions for the ancient globin family: bacterial responses to nitric oxide and nitrosative stress. Mol Microbiol 36: 775-83. 40. Torfgard KE, Ahlner J (1994) Mechanism of action of nitrates. Cardiovasc Drug Ther 8: 701-17.

41. Feelisch M, Noack EA (1987) Correlation between nitric oxide formation during degradation of organic nitrates and activation of guanylatecyclise. Eur J Pharmacol 139: 19-30.

42. Thomas DD, Espey MG, Vitek MP, Miranda KM, Wink DA (2002) Protein nitration is mediated by heme and free metals through Fenton-type chemistry: an alternative to the NO/O2- reaction. Proc Natl Acad Sci USA 99: 12691-6.

43. Ischiropoulos H (1998) Biological tyrosine nitration: a pathophysiological function of nitric oxide and reactive oxygen species. Arch Biochem Biophys 356: 1-11. 44. Bian K, Gao Z, Weisbrodt N, Murad F (2003) The nature of heme/iron-induced protein tyrosine nitration. Proc Natl Acad Sci USA $100: 5712-7$.

45. Lozinsky OV, Lushchak OV, Kryshchuk NI, Shchypanska NY, Riabkina AH, et al. (2013) S-nitrosoglutathione-induced toxicity in Drosophila melanogaster: Delayed pupation and induced mild oxidative/nitrosative stress in eclosed flies. Comp Biochem Physiol A Mol Integr Physiol 164: 162-70. 
46. Lushchak OV, Lushchak VI (2008) Sodium nitroprusside induces mild oxidative stress in Saccharomyces cerevisiae. Redox Rep 13: 144-52.

47. Tórtora V, Quijano C, Freeman B, Radi R, Castro L (2007) Mitochondrial aconitase reaction with nitric oxide, S-nitrosoglutathione, and peroxynitrite: mechanisms and relative contributions to aconitase inactivation. Free Radic Biol Med 42: 1075-1088.

48. Anderson ME (1998) Glutathione: an overview of biosynthesis and modulation. Chem Biol Interact 111: 1-14.

49. Lushchak VI (2011) Glutathione homeostasis and functions: potential targets for medical interventions. J Amino Acids 2012: 1-26.

50. Clancy RM, Levartovsky D, Leszczynska-Piziak J, Yegudin J, Abramson SB (1994) Nitric oxide reacts with intracellular glutathione and activates the hexose monophosphate shunt in human neutrophils: evidence for S-nitrosoglutathione as a bioactive intermediary. Proc Natl Acad Sci USA 91: 3680-4.

51. de Belder AJ, MacAllister R, Radomski MW, Moncada S, Vallance PJ (1994) Effects of S-nitroso-glutathione in the human forearm circulation: evidence for selective inhibition of platelet activation. Cardiovasc Res 28: 691-4.

52. Marcondes S, Turko IV, Murad F (2001) Nitration of succinyl-CoA:3-oxoacid CoA-transferase in rats after endotoxin administration. PNAS 98: 7146-51.

53. Souza JM, Peluffo G, Radi R (2008) Protein tyrosine nitration-Functional alteration or just a biomarker? Free Radic Biol Med 45: $357-66$.

54. Radi R (2013) Protein tyrosine nitration: biochemical mechanisms and structural basis of its functional effects. Acc Chem Res 46: $550-9$.

55. Osoata GO, Yamamura S, Ito M, Vuppusetty C, Adcock IM, et al. (2009) Nitration of distinct tyrosine residues causes inactivation of histone deacetylase 2 . Biochem Biophys Res Commun 384: 366-71.

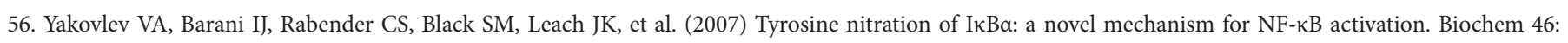
11671-83.

57. Karthikeyan T, Pravin M, Muthusamy VS, Raja RB, Lakshmi BS (2013) In Vitro Investigation of the Immunomodulatory Potential of Probiotic Lactobacillus casei. Probiotics \& Antimicro Prot 5: 51-8.

58. Takakusa H, Mohar I, Kavanagh TJ, Kelly EJ, Kaspera R, et al. (2012) Protein tyrosine nitration of mitochondrial carbamoyl phosphate synthetase 1 and its functional consequences. Biochem Biophys Res Commun 420: 54-60.

59. Begara-Morales JC, Sánchez-Calvo B, Chaki M, Valderrama R, Mata-Pérez C, et al. (2013) Dual regulation of cytosolic ascorbate peroxidase (APX) by tyrosine nitration and S-nitrosylation. J Exp Bot 65: 527-38.

60. Ohmori H, Oka M, Nishikawa Y, Shigemitsu H, Takeuchi M, et al. (2005) Immunogenicity of autologous IgG bearing the inflammation-associated marker 3-nitrotyrosine. Immunol Lett 96: 47-54.

61. Losman MJ, Fasy TM, Novick KE, Monestier M (1992) Monoclonal autoantibodies to subnucleosomes from a MRL/MP-+/+ mouse. Oligoclonality of the antibody response and recognition of a determinant composed of histones H2A, H2B and DNA. J Immunol 48: 1561-9.

62. Yang B, Rizzo V (2007) TNF- $\alpha$ potentiates protein tyrosine nitration through activation of NADPH oxidase and eNOS localized in membrane rafts and caveolae of bovine aortic endothelial cells. Am J Physiol Heart Circ Physiol 292: H954-62.

63. Shishehbor MH, Aviles RJ, Brennan M, Fu X, Goormastic M, et al. (2003) Association of nitrotyrosine levels with cardiovascular disease and modulation by statin therapy. JAMA 289: 1675-80.

64. Gamblin TC, Chen F, Zambrano A, Abraha A, Lagalwar S, et. al. (2003) Caspase cleavage of tau: linking amyloid and neurofibrillary tangles in Alzheimer's disease. Proc Natl Acad Sci USA 100: 10032-7.

65. Goedert M, Spillantini MG, Jakes R, Rutherford D, Crowther RA (1989) Multiple isoforms of human microtubule-associated protein tau: sequences and localization in neurofibrillary tangles of Alzheimer's disease. Neuron 3: 519-26.

66. Reynolds MR, Berry RW, Binder LI (2005) Site-specific nitration differentially influences tau assembly in vitro. Biochem 44: $13997-4009$.

67. Chen X, Yan SD (2006) Mitochondrial Abeta: a potential cause of metabolic dysfunction in Alzheimer's disease. IUBMB Life 58: 686-94.

68. Jomova K, Vondrakova D, Lawson M, Valko M (2010) Metals, oxidative stress and neurodegenerative disorders. Mol Cell Biochem 345: $91-104$.

69. Chavarría C, Souza JM (2013) Oxidation and nitration of $\alpha$-synuclein and their implications in neurodegenerative diseases. Arch Biochem Biophys 533: 25-32. 70. Souza JM, Giasson BI, Chen Q, Lee V, Ischiropoulos H (2000) Dityrosine cross-linking promotes formation of stable alpha -synuclein polymers. Implication of nitrative and oxidative stress in the pathogenesis of neurodegenerative synucleinopathies. J Biol Chem 275: 18344-9.

71. Danielson SR, Held JM, Schilling B, Oo M, Gibson BW, et al. (2009) Preferentially increased nitration of a-synuclein at tyrosine-39 in a cellular oxidative model of Parkinson's disease. Anal Chem 81: 7823-8.

72. Takahashi T, Yamashita H, Nakamura T, Nagano Y, Nakamura S (2002) Tyrosine 125 of a-synuclein plays a critical role for dimerization following nitrative stress. Brain Res 938: 73-80.

73. Hodara R, Norris EH, Giasson BI, Mishizen-Eberz AJ, Lynch DR, et al. (2004) Functional consequences of alpha-synuclein tyrosine nitration: diminished binding to lipid vesicles and increased fibril formation. J Biol Chem 279: 47746-53.

74. Upmacis RK (2008) Atherosclerosis: A link between lipid intake and protein tyrosine nitration. Lipid Insights 2008: 75-88.

75. Reyes JF, Fu Y, Vana L, Kanaan NM, Binder LI (2011) Tyrosine nitration within the proline-rich region of tau in Alzheimer's Disease. Am J Pathol 178: 2275-85.

76. Upmacis RK, Deeb RS, Hajjar DP (2001) Role of nitrogen oxides on eicosanoid production during atherosclerosis: understanding the controversies. Curr Atheroscler Rep 3: 181-2.

77. Deeb RS, Shen H, Gamss C, Gavrilova T, Summers BD, et al. (2006) Inducible nitric oxide synthase mediates prostaglandin h2 synthase nitration and suppresses eicosanoid production. Am J Pathol 168: 349-62.

78. Vadseth C, Souza JM, Thomson L, Seagraves A, Nagaswami C, et al. (2004) Pro-thrombotic state induced by post-translational modification of fibrinogen by reactive nitrogen species. J Biol Chem 279: 8820-6.

79. Zheng L, Nukuna B, Brennan ML, Sun M, Goormastic M, et al. (2004) Apolipoprotein A-I is a selective target for myeloperoxidasecatalyzed oxidation and functional impairment in subjects with cardiovascular disease. J Clin Invest 114: 529-41.

80. Gow AJ, Duran D, Malcolm S, Ischiropoulos H (1996) Effects of peroxynitrite-induced protein modifications on tyrosine phosphorylationand degradation. FEBS Lett 385: 63-6.

81. Turko IV, Murad F (2002) Protein nitration in cardiovascular diseases. Pharmacol Rev 54: 619-34.

82. Kong SK, Yim MB, Stadtman ER, Chock PB (1996) Peroxynitrite disables the tyrosine phosphorylation regulatory mechanism: lymphocyte-specific tyrosine kinase fails to phosphorylate nitrated cdc2(6-20)NH2 peptide. Proc Natl Acad Sci USA 93: 3377-81. 
83. Saeki M, Maeda S (1999) P130cas is a cellular target protein for tyrosine nitration induced by peroxynitrite. Neurosci Res 33: $325-8$.

84. Pinzar E, Wang T, Garrido MR, Xu W, Levy P, et al. (2005) Angiotensin II induces tyrosine nitration and activation of ERK1/2 in vascular smooth muscle cells. FEBS Lett 579: 5100-4.

85. Kleinknecht A, Popova B, Lázaro DF, Pinho R, Valerius O, et al. (2016) C-terminal tyrosine residue modifications modulate the protective phosphorylation of serine 129 of a-Synuclein in a yeast model of Parkinson's Disease. PLoS Genet 12: 1-39.

86. Monteiro HP (2002) Signal transduction by protein tyrosine nitration: competition or cooperation with tyrosine phosphorylation dependent signaling events? Free Radic Biol Med 33: 765-73.

87. Brito C, Naviliat M, Tiscornia AC, Vuillier F, Gualco G, et. al. (1999) Peroxynitrite inhibits T lymphocyte activation and proliferation by promoting impairment of tyrosine phosphorylation and peroxynitrite-driven apoptotic death. J Immunol 162: 3356-66.

88. Takakura K, Beckman JS, MacMillan-Crow LA, Crow JP (1999) Rapid and irreversible inactivation of protein tyrosine phosphatases PTP1B, CD45, and LAR by peroxynitrite. Arch Biochem Biophys 369: 197-207.

89. Heijnen HF, Donselaar EV, Slot JW, Fries DM, Blachard-Fillion B, et al. (2006) Subcellular localization of tyrosine nitrated proteins is dictated by reactive oxygen species generating enzymes and by proximity to nitric oxide synthase. Free Radic Biol Med 40: 1903-13.

90. Radi R, Cassina A, Hodara R, Quijano C, Castro L (2002) Peroxynitrite reactions and formation in mitochondria. Free Radic Biol Med 3: 1451-64.

91. Koeck T, Fu X, Hazen SL, Crabb JW, Stuehr DJ, et al. (2004) Rapid and selective oxygen-regulated protein tyrosine denitration and nitration in mitochondria. J Biol Chem 279: 27257-62.

92. MacMillan-Crow LA, Cruthirds DL, Ahki KM, Sanders PW, Thompson JA (2001) Mitochondrial tyrosine nitration precedes chronic allograft nephropathy. Free Radic Biol Med 31: 1603-8.

93. Ren XY, Li YN, Qi JS, Niu T (2008) Peroxynitrite-induced proteinnitration contributes to liver mitochondrial damage in diabetic rats. J Diabetes Complications 22: 357-64.

94. Turko IV, Li L, Aulak KS, Stuehr DJ, Chang JY, et al. (2003) Protein tyrosine nitration in the mitochondria from diabetic mouse heart. Implications to dysfunctional mitochondria in diabetes. J Biol Chem 278: 33972-7.

95. Aulak KS, Koeck T, Crabb JW, Stuehr DJ (2004) Proteomic method for identification of tyrosine-nitrated proteins. Methods Mol Biol 279: 151-65.

96. Koeck T, Stuehr DJ, Aulak KS (2005) Mitochondria and regulated tyrosine nitration. Biochem Soc Trans 33: $1399-403$.

97. Leger CL, Torres-Rasgado E, Fouret G, Carbonneau MA (2008) First evidence for an LDL- and HDL-associated nitratase activity that denitrates albumin-bound nitrotyrosine-physiological consequences. IUBMB Life 60: 73-8.

98. Sabetkar M, Low SY, Naseem KM, Bruckdorfer KR (2002) The nitration of proteins in platelets: significance in platelet function. Free Radic Biol Med 33: 728-36. 99. Smallwood HS, Lourette NM, Boschek CB, Bigelow DJ, Smith RD, et al. (2007) Identification of adenitrase activity against calmodulin in activated macrophages using high-field liquid chromatography--FTICR mass spectrometry. Biochem 46: 10498-505.

100. Deeb RS, Nuriel T, Cheung C, Summers B, Lamon BD, et al. (2013) Characterization of a cellular denitrase activity that reverses nitration of cyclooxygenase. Am J Physiol Heart Circ Physiol 305: H687-98.

101. Predescu D, Pedrescu S, Malik AB (2002) Transport of nitrated albumin across continuous vascular endothelium. Proc Natl Acad Sci USA 99: $13932-7$.

102. Kuo WN, Kanadia RN, Shanbhag VP, Toro R (1999) Denitration of peroxynitrite-treated proteins by 'protein nitratases' from rat brain and heart. Mol Cell Biochem 201: 11-6.

103. Chen HJ, Chang CM, Plin W, Cheng DL, Leong MI (2008) H2O2/nitrite-induced post-translational modifications of human hemoglobin determined by mass spectrometry: redox regulation of tyrosine nitration and 3-nitrotyrosine reduction by antioxidants. Chembiochem 9: 312-23.

104. Irie Y, Saeki M, Kamisaki Y, Martin E, Murad F (2003) Histone H1.2 is a substrate for denitrase, an activity that reduces nitrotyrosine immunoreactivity in proteins. Proc Natl Acad Sci USA 100: 5634-9

105. Aulak KS, Koeck T, Crabb JW, Steuhr DJ (2004) Dynamics of protein nitration in cells and mitochondria. Am J Physiol Heart Circ Physiol 286: H30-8.

106. Koeck T, Fu X, Hazen SL, Crabb JW, Stuehr DJ, et. al. (2004) Rapid and selective oxygen-regulated protein tyrosine denitration and nitration in mitochondria. J Biol Chem 279: 27257-62.

107. Teixeira D, Fernandes R, Prudencio C, Vieira M (2016) 3-Nitrotyrosine quantification methods: Current concepts and future challenges. Biochimie 125: 1-11. 108. Herce-Pagliai C, Kotecha S, Shuker DE (1998) Analytical methods for 3-nitrotyrosine as a marker of exposure to reactive nitrogen species: a review. Nitric Oxide 2: 324-36

109. Greenacre SA, Ischiropoulos H (2001) Tyrosine nitration: Localisation, quantification, consequences for protein function and signal transduction. Free Radic Res 34: 541-81.

110. Tsikas D (2012) Analytical methods for 3-nitrotyrosine quantification in biological samples: the unique role of tandem mass spectrometry. Amino Acids 42: 45-63.

111. Kanski J, Behring A, Pelling J, Schoneich C (2005) Proteomic identification of 3-nitrotyrosine-containing rat cardiac proteins: effects of biological aging. Am J Physiol Heart Circ Physiol 288: H371-81.

112. Franze T, Weller MG, Niessner R, Poschl U (2004) Comparison of nitrotyrosine antibodies and development of immunoassays for the detection of nitrated proteins. Analyst 129: 589-96.

113. Crow JP, Ischiropoulos H (1996) Detection and quantitation ofnitrotyrosine residues in proteins: in vivo marker of peroxynitrite. Methods Enzymol 269: 185-94.

114. Hensley K, Maidt M, Pye Q, Stewart C, Wack M, et al. (1997) Quantitation of protein-bound 3-nitrotyrosine and 3,4-dihydroxyphenylalanine by high-performance liquid chromatography with electrochemical array detection. Anal Biochem 251: 187-95.

115. Giese R, Riordan J (1975) Nitrotyrosine internal standard for amino acid analysis. Anal Biochem 64: 588-92.

116. Sarver A, Scheffler NK, Shetlar MD, Gibson BW (2001) Analysis of peptides and proteins containing nitrotyrosine by matrixassisted laser desorption/ionization mass spectrometry. J Am Soc Mass Spectrom 12: 439-48.

117. Crowley JR, Yarasheski K, Leeuwenburgh C, Turk J, Heinecke JW (1998) Isotope dilution mass spectrometric quantification of 3-nitrotyrosine in proteins and tissues is facilitated by reduction to 3-aminotyrosine. Anal Biochem 259: 127-35.

118. Lundgren DH, Han DK, Eng JK (2005) Protein identification using TurboSEQUEST. Curr Protoc Bioinformatics doi: 10.1002/0471250953.bi1303s10. 
119. Searle BC (2010) Scaffold: a bioinformatic tool for validating MS/MS-based proteomic studies. Proteomics 10: 1265-9.

120. Han Y, Ma B, Zhang K (2005) SPIDER: Software for Protein Identification from Sequence Tags with De Novo Sequencing Error. J Bioinform Comput Biol 3: 697-716

121. Yeo WS, Kim YJ, Kabir MH, Kang JW, Kim KP (2015) Mass spectrometric analysis of protein tyrosine nitration in aging and neurodegenerative diseases. Mass Spectrom Rev 34: 166-83.

122. Jones DT (1999) Protein secondary structure prediction based on position-specific scoring matrices. J Mol Biol 292: 195-202.

123. McGuffin LJ, Bryson K, Jones DT (2000) The PSIPRED protein structure prediction server. Bioinformatics 16: 404-5.

124. Cuff JA, Barton GJ (2000) Application of multiple sequence alignment profiles to improve protein secondary structure prediction. Proteins 40: 502-11.

125. Ouali M, King RD (2000) Cascaded multiple classifiers for secondary structure prediction. Protein Sci 9: 1162-76.

126. Rost B (2001) Review: protein secondary structure prediction continues to rise. J Struct Biol 134: $204-18$.

127. Drozdetskiy A, Cole C, Procter J, Barton G J (2015) JPred4: a protein secondary structure prediction server. Nucleic Acids Res 43: W389-94.

128. Liu Z, Cao J, Ma Q, Gao X, Ren J, et al. (2011) GPS-YNO2: computational prediction of tyrosine nitration sites in proteins. MolBiosyst 7: $1197-204$.

129. Joo K, Lee SJ, Lee J (2012) Sann: solvent accessibility prediction of proteins by nearest neighbor method. Proteins 80: 1791-7.

130. Pieroni E, Bentem SF, Mancosu G, Capobianco E, Hirt H, et. al. (2008) Protein networking: insights into global functional organization of proteomes. Proteomics 8: 799-816.

131. Xenarios I, Salwinski L, Duan XJ, Higney P, Kim S, et al. (2002) DIP, the Database of Interacting Proteins: a research tool for studying cellular networks of protein interactions. Nucleic Acids Res 30: 303-5.

132. Deane CM, Salwinski L, Xenarios i, Eisenberg D (2002) Protein Interactions, two methods for assessment of the reliability of high throughput observations. Mol Cell Proteomics 1: 349-56.

133. Bader GD, Betel D, Hogue CWV (2003) BIND: the Biomolecular Interaction Network Database. Nucleic Acids Res 31: 248-50.

134. Zanzoni A, Montecchi-Palazzi L, Quondam M, Ausiello G, Helmer-Citterich M, et al. (2002) MINT: a Molecular INTeraction database. FEBS Lett 513: 135-40. 135. Pagel P, Kovac S, Oesterheld M, Brauner B, Dunger-Kaltenbach I, et al. (2005) The MIPS mammalian protein-protein interaction database. Bioinformatics 21: $832-4$.

136. Smoot ME, Ono K, Ruscheinski J, Wang P, Ideker T (2011) Cytoscape 2.8: new features for data integration and network visualization. Bioinformatics 27: 431-2.

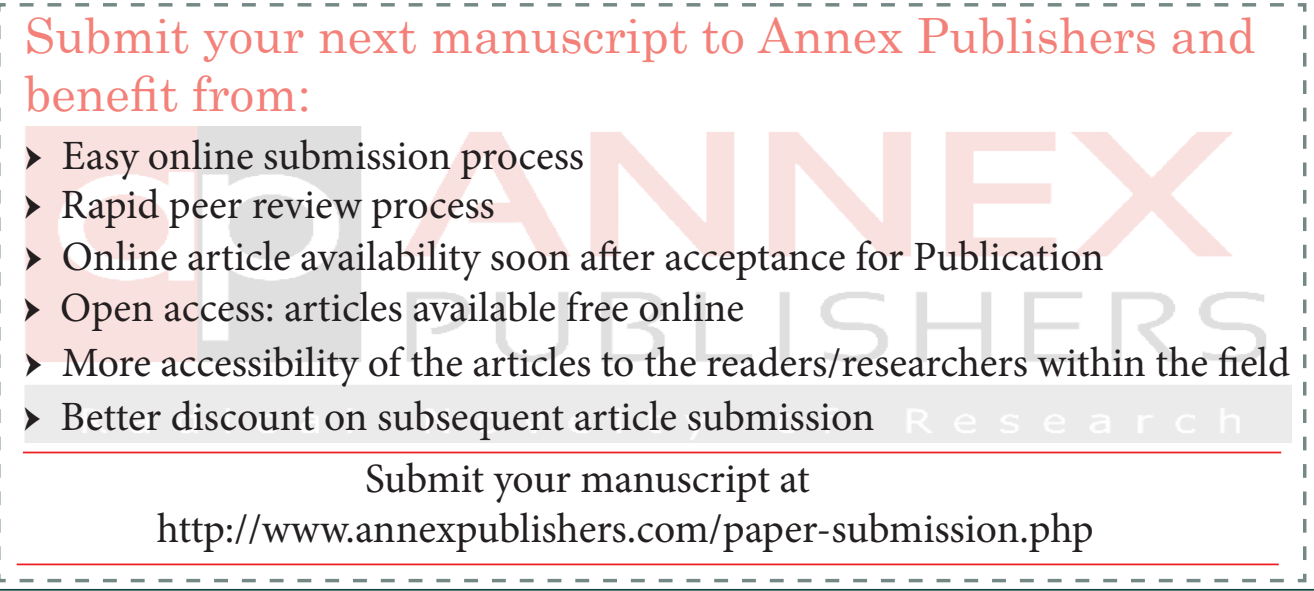

